\title{
O funcionamento semântico do par de advérbios já e ainda
}

\author{
Claudia Mendes Campos \\ Universidade Federal do Paraná (UFPR), Curitiba, Paraná, Brasil \\ c.mendescampos@gmail.com \\ https://orcid.org/0000-0002-1558-2213
}

DOI: $\underline{\text { http://dx.doi.org/10.21165/el.v47i1.1967 }}$

\section{Resumo}

Este artigo toma os advérbios já e ainda como um par semântico e os descreve um em relação ao outro. Entende-se que ambos os advérbios marcam uma temporalidade, implicitam uma expectativa e introduzem um pressuposto, sendo a indicação da temporalidade o conteúdo posto. O já indica que a situação descrita pelo verbo aconteceu antes ou depois do momento da enunciação, ou de um momento de referência; o ainda indica que a situação ocorre no momento da enunciação ou no momento de referência. O já traz o implícito de que a situação é esperada, que sua ocorrência é possível; o ainda traz o implícito de que não se esperaria a continuidade da situação. O já introduz o pressuposto de que a situação não ocorria antes; o ainda introduz o pressuposto de que a situação já ocorria antes.

Palavras chave: advérbios; temporalidade; expectativa; pressuposição.

\section{The semantic functioning of the pair of adverbs already and still}

\begin{abstract}
This article considers the adverbs já (already) and ainda (yet/still) as a semantic pair and describes them in relation to each other. Both adverbs mark a temporality, imply an expectation and introduce a presupposition; besides, the expressed content is the indication of the temporality. Já (already) indicates that the situation described by the verb happened before or after the enunciation moment, or a reference moment; ainda (yet/still) indicates that the situation occurs at the enunciation moment or at the reference moment. Já (already) implies that the situation is expected, that its occurrence is possible; ainda (yet/still) implies that one would not expect the situation to continue. Já (already) introduces the presupposition that the situation did not happen before; ainda (yet/still) introduces the presupposition that the situation had already occurred before.
\end{abstract}

Keywords: adverbs; temporality; expectancy; presupposition.

\section{Introdução}

Os advérbios já e ainda estabelecem entre si uma relação nem sempre explorada nas gramáticas que os descrevem. No entanto, mesmo intuitivamente podemos identificar aspectos dessa relação, por exemplo, quando observamos a sua negação: a negação de um deles se faz com o outro advérbio do par junto à partícula de negação - assim, para negar que "Pedro já sabe ler", podemos dizer que "Pedro ainda não sabe ler". Esta relação não é, todavia, pari passu em todos os seus detalhes. Há certamente pontos em que vemos um espelhamento entre as suas descrições e outros pontos em que há um maior distanciamento no seu modo de funcionamento. 
Nesse sentido, este trabalho visa descrever e discutir o funcionamento desses advérbios tomados como um par. Isto é, ficam de fora desta reflexão outros usos desses operadores, tais como aqueles em que o já opera como um focalizador ("João estuda piano, já Miguel estuda violão") ou em que o ainda pode ser substituído por "também" ou por "mesmo" ("João tem dois cachorros e ainda cuida de três gatos"). Além disso, por uma questão de espaço, a análise se limitará aos usos desses advérbios em adjacência verbal, ficando para um outro momento a descrição do seu funcionamento junto a outras classes gramaticais que não o verbo.

Outros autores se detiveram sobre pelo menos um desses operadores, com diferentes enfoques teóricos, com maior ou menor profundidade. Cabe destacar alguns deles aqui: Ducrot (1972, 1981), Zamboni (1978), Martelotta (1993, 2012), Neves (2000), Castilho e Ilari (2008), Castilho (2010) e Raposo (2013). Estes autores levantam aspectos complementares do funcionamento desses operadores, destacando características que também encontrei em meus dados. Não vou resenhar todas essas análises neste momento, especialmente em função do recorte necessário em um artigo desta natureza. Partirei da reflexão feita por Raposo, apontando aspectos em que o olhar de outros desses linguistas permite esclarecer o funcionamento semântico dos advérbios em foco, porém sem pretender exaustividade.

Há aspectos semânticos e enunciativos do funcionamento dos advérbios já e ainda que caberia destacar. Nesse sentido, a significação é entendida aqui como tendo uma dupla dimensão, uma vez que é afetada pelo sistema da língua e por sua colocação em uso por um locutor. Isto é, entendo que há aspectos do funcionamento desses operadores que se devem às suas relações internas ao sistema linguístico, enquanto, por outro lado, há outros aspectos colocados em cena apenas quando o discurso entra em ação. Em "A forma e o sentido na linguagem", artigo originalmente publicado em 1966, Benveniste (1989) estabelece dois domínios de funcionamento da língua: o semiótico (base em que os signos estão organizados em paradigmas) e o semântico (sintagmatização das palavras pela "língua-discurso"). Enquanto o semiótico é "uma propriedade da língua", fruto da rede de relações e oposições que se dão dentro do sistema, o semântico é resultado de "uma atividade do locutor, que coloca a língua em ação" e diz respeito à produção do discurso (BENVENISTE, 1989, p. 230). Desse modo, para Benveniste, o semiótico oferece um número limitado de lexemas e esquemas sintáticos, que são usados em sintagmatizações (encadeamentos), que resultam, no semântico, em uma multiplicidade de frases possíveis.

Neste artigo, pretendo oferecer uma descrição possível para o que Benveniste denominaria de funcionamento semiótico dos advérbios em análise, fazendo um estudo das relações entre os dois operadores (através de testes de substituição, de negação), assim como entre os dois operadores e as outras unidades do sistema com as quais eles formam cadeia. Em outras palavras, procuro os "esquemas sintáticos" (BENVENISTE, op. cit., p. 234) em que o par já e ainda pode aparecer na língua portuguesa, sem perder de vista que pode haver diferenças em relação a seu funcionamento semântico (em termos benvenistianos) ou enunciativo (em termos correntes), que não serão, no entanto, desenvolvidas neste momento.

Para fazer as análises, foram selecionados enunciados jornalísticos de gêneros variados, tanto da mídia impressa quanto digital, identificados via sistema de busca eletrônica, especialmente nos canais vinculados à plataforma UOL. Também foram 
utilizados alguns enunciados infantis, não inusitados nem agramaticais, selecionados da fala de uma criança entre seus cinco e seis anos, sujeito da pesquisa em aquisição da linguagem que desenvolvo. ${ }^{1}$ Os enunciados foram tomados como recortes de textos (cf. GUIMARÃES, 2007), considerando sempre sua relação com o todo de que fazem parte, assim como com a incompletude e a polissemia características da linguagem (ORLANDI, 1984, apud GUIMARÃES, 2007).

\section{O advérbio já}

\subsection{A localização temporal}

A primeira característica destacada por Raposo (2013) no funcionamento semântico do advérbio já diz respeito à localização temporal da situação descrita pelo verbo ao qual o advérbio se liga: ela ocorre sempre antes do momento da enunciação ou de um momento de referência indicado no texto ou no contexto. $\mathrm{O}$ advérbio pode aparecer tanto com verbos em tempos imperfectivos quanto perfectivos, esta diferença de aspecto implicando uma diferença nos efeitos promovidos pelo advérbio no enunciado. Se o verbo estiver no imperfectivo, o advérbio indicará que a situação, em curso, se iniciou antes da enunciação ou antes do momento de referência, podendo permanecer ocorrendo durante a enunciação e mesmo depois dela, ou durante e depois do momento de referência. Quando o verbo está no imperfectivo, não se diz se a situação se completou ou não (cf. LYONS, 1979), ela é entendida como tendo algum tipo de estrutura interna (TRASK, 2004), de maneira que ela pode se estender para além do momento da enunciação. Já se o verbo estiver no perfectivo, o advérbio indicará que a situação, concluída, ocorreu em momento anterior à enunciação ou anterior a um momento de referência estabelecido no enunciado ou no contexto. Quando o verbo está no perfectivo, a situação é descrita como completa (LYONS, op. cit.), tomada como "um todo não passível de análise" (TRASK, op. cit.), de maneira que ela não pode se estender para além do limite da enunciação, ou do momento de referência. ${ }^{2}$ Assim, o advérbio sofre os efeitos de se ligar a um ou outro aspecto verbal, sem, contudo, indicar qual seja ele, ou modificá-lo. Nesse sentido, podemos afirmar que se trata de um advérbio com efeitos de sentido sobre a localização temporal $^{3}$ dos eventos descritos pelo verbo ao qual ele se liga, afetado pelo aspecto dos verbos. Vejamos os enunciados a seguir, que exemplificam esse funcionamento:

\footnotetext{
1 A motivação original desta pesquisa é a análise do funcionamento desses operadores na fala infantil, discussão que será desenvolvida em um momento posterior à descrição do funcionamento semântico e enunciativo dos advérbios em foco. A razão para o uso, aqui, de dados aparentemente tão díspares é justamente a intenção de investigar o funcionamento desses operadores na língua, para então investigar seu funcionamento na linguagem da criança.

${ }^{2}$ Em ambos os casos, o advérbio não indica o momento exato em que a situação ocorreu ou teve início, ele apenas indica que isso se deu antes em algum momento passado. Desse modo, pode ser que a situação tenha ocorrido ou se iniciado há bastante tempo, ou há pouquíssimo tempo, quase imediatamente antes da enunciação ou da referência, sem que o advérbio diga nada sobre isso.

${ }^{3} \mathrm{Na}$ medida em que se trata de uma localização temporal apenas em termos de "antes" e "depois", poderíamos talvez falar em relação temporal. Afinal, a anterioridade e a posterioridade se dão sempre em relação a alguma coisa. No entanto, vou preferir a expressão "localização", para seguir a formulação de Raposo.
} 
(1) Pedro já está em casa. [Aspecto imperfectivo, tempo presente]

Pedro chegou em casa antes do momento da enunciação e permanece em casa no momento da enunciação.

(2) As possibilidades técnicas para combinar automaticamente as contas de usuários no Facebook e no WhatsApp já existiam em 2014 Iquando o acordo de aquisição do WhatsApp pelo Facebook foi analisado pelos órgãos reguladores antitruste da União Europeia]. [Aspecto imperfectivo, tempo pretérito imperfeito]

As possibilidades técnicas começaram a existir antes da análise do acordo de aquisição $e$ continuaram a existir durante e depois dela (momento de referência recuperado no texto).

(3) Pedro já chegou em casa. [Aspecto perfectivo, tempo pretérito perfeito]

A chegada de Pedro em casa aconteceu, e se concluiu, antes do momento da enunciação.

(4) Pedro já tinha fechado a janela [quando João foi até o quarto verificar se ela estava fechada]. [Aspecto perfectivo, tempo pretérito mais que perfeito]

A janela foi fechada antes de João ir até o quarto (momento de referência recuperado contextualmente).

Este mesmo advérbio pode também indicar que a situação descrita pelo verbo irá ocorrer depois do momento da enunciação ou de um ponto de referência no futuro, a depender do tempo do verbo ao qual ele se liga. Se o verbo estiver no futuro do presente, ou no presente do indicativo com sentido de futuro, então a localização temporal se dá em termos de futuro, apontando para adiante no tempo em vez de para trás. Há ainda a possibilidade de o advérbio indicar que a situação vai se dar no futuro, mas antes de um momento de referência estabelecido no texto ou no contexto, se o tempo do verbo for o futuro do presente composto com o verbo ter (ter [futuro do presente] + verbo [particípio]). No caso de o verbo estar no futuro do pretérito, o advérbio parece indicar que a situação descrita, embora seja apenas uma possibilidade, uma hipótese, se ocorrer, ocorrerá no futuro, seja depois do momento da enunciação, seja depois de um momento de referência. Os exemplos 5 a 8 , a seguir, trazem esse modo de funcionamento.

(5) Quando a criança fizer oito anos, já vão ter caído muitos de seus dentes. [Tempo futuro do presente composto (ir [presente] + ter + participio)]

Os dentes terão caído no futuro, mas antes de a criança fazer oito anos (momento de referência dado no texto).

(6) Pedro já vai guardar os brinquedos. [Tempo futuro do presente composto (ir [presente] + infinitivo)]

Pedro irá guardar os brinquedos depois do momento da enunciação.

(7) Assim que a obra for entregue, um posto da Polícia Militar já irá começar a funcionar para ajudar no policiamento da regiấo do memorial. [Tempo futuro do presente composto (ir [futuro do presente] + infinitivo)]

O posto da Polícia Militar vai começar a funcionar depois que a obra for entregue (momento de referência dado no texto).

(8) Uma parada no ritmo de redução [da taxa Selic] já seria suficiente para colocar um freio no movimento até então tímido de queda dos juros cobrados nos empréstimos bancários. [Tempo futuro do pretérito]

A parada no ritmo de redução da taxa Selic, se ocorrer, ocorrerá depois do momento da enunciação. 
Podemos, assim, afirmar que a localização temporal é parte dos sentidos deste advérbio, ou é parte do funcionamento semiótico deste advérbio, para usar os termos de Benveniste. Isto é, trata-se aqui de uma caracterização sistêmica do seu funcionamento, de uma característica que diz respeito à ordem própria da língua.

\subsection{A expectativa, ou probabilidade}

De acordo com Raposo (2013), o já indica também a expectativa dos interlocutores de que a situação descrita vai ou pode vir a acontecer. Ele confirmaria essa expectativa.

Segundo este autor, a expectativa de que a situação descrita pode vir a acontecer sempre está presente nos usos do advérbio já. Assim, seria estranho usar o já para falar de uma situação que ninguém achasse que poderia acontecer (por exemplo, uma criança dizer "eu já estou pequeno", ou um repórter dar uma notícia inesperada como se fosse esperada, afirmando "o rio já está pegando fogo"). Portanto, tem de haver sempre alguma probabilidade quando se usa o já. Não se trata, portanto, exatamente, de uma expectativa de que a situação vá, de fato, acontecer, mas de que ela pode vir a acontecer. A expectativa pode ser, inclusive, no discurso, a de que a situação não vai acontecer, embora se reconheça que ela pode acontecer. Isto é, tem de haver um reconhecimento da possibilidade de ela vir a acontecer, como podemos ver nas análises abaixo dos enunciados de 9 a 13, que exemplificam, por um lado, a expectativa de que a situação ocorra e, por outro lado, a assunção de que é possível que a situação venha a acontecer. Já o exemplo 14 mostra que basta haver a possibilidade de que a situação ocorra, ainda que a expectativa discursiva seja contrária à ocorrência.

(9) Hoje já é dia 2. $\rightarrow$ Era de se esperar que o dia 2 chegasse. / Hoje podia ser dia 2.

(10) Eu já sou grande. $\rightarrow$ Era de se esperar que a criança ficasse grande. / A criança podia ficar grande.

(11) As negociações já estão bem adiantadas. $\rightarrow$ Era de se esperar que as negociações ficassem adiantadas/ se adiantassem. / As negociações podiam ficar adiantadas.

(12) Um ministro já defendia o desembarque [a saída do seu partido da base aliada do governo] na noite de quarta. $\rightarrow$ Era de se esperar que o ministro defendesse o desembarque. / O ministro podia vir a defender o desembarque.

(13) A oposição já protocolou pedido de impeachment. $\rightarrow$ Era de se esperar que a oposição protocolasse pedido de impeachment. / A oposição podia vir a protocolar pedido de impeachment.

(14) Para sorte do governo, ao menos o acerto com os Estados já havia passado antes da eclosão das gravações da JBS. $\rightarrow$ Era possível que o acerto com os Estados ocorresse e o governo esperava que acontecesse. / O acerto podia vir a ocorrer. / Porém, o texto dá a entender que não era de se esperar que ele ocorresse, dadas as condições do governo naquele momento.

Mesmo quando o verbo está no futuro e a localização temporal indica que a situação vai ocorrer depois da enunciação ou de um momento de referência futuro, a expectativa, no sentido de possibilidade de ocorrência, também aparece como uma característica do advérbio. $\mathrm{O}$ mesmo ocorre quando o advérbio indica que a situação descrita pelo verbo vai acontecer no futuro, mas antes de um momento de referência. Vejamos alguns exemplos: 
Meus pais já vão abrir a porta para você (criança falando para uma pessoa que tocara a campainha da sua casa). $\rightarrow$ Era de esperar que a porta fosse aberta para o visitante. / A porta poderia vir a ser aberta para o visitante. ${ }^{4}$

(16) Na quarta-feira, a frente fria já vai ter se afastado da costa do Rio de Janeiro. $\rightarrow$ Era de se esperar que a frente fria se afastasse. / A frente fria podia vir a se afastar.

Pode ocorrer, ainda, segundo Raposo, que o advérbio já indique a expectativa de que a situação descrita pelo verbo devesse ocorrer em outro momento, anterior (caso em que o já poderia ser substituído por finalmente ou por fim - "o bebê já nasceu" / "finalmente o bebê nasceu") ou posterior ("o dente da criança de três anos já caiu") ao que de fato ocorreu. Esse segundo caso foi encontrado entre os dados da pesquisa, enquanto o primeiro não o foi, talvez em função de diferenças entre o português do Brasil e o europeu. De qualquer maneira, esse uso diferenciado do advérbio em foco coloca em cena o discurso na interpretação dos enunciados - estamos no domínio semântico. Vejamos o exemplo que ocorreu nos dados da pesquisa:

O governador do Rio, Luiz Fernando Pezão, disse, nesta quinta (18), que uma saída do presidente Michel Temer seria "muito difícil" para a economia. "É tudo muito ruim para o país, que já tem dois presidentes em apenas três anos." $\rightarrow$ Seria de se esperar que o país tivesse dois presidentes em mais tempo, ou em um momento posterior. / A existência de dois presidentes ocorreu antes do tempo esperado (que seria no mínimo superior a quatro anos, tempo de um mandato).

Como afirmei acima, há alguns usos desse advérbio em que a indicação de expectativa se apresenta como uma contra-expectativa. $\mathrm{O}$ exemplo acima (17) pode ser interpretado como um desses casos, uma vez que o já pode estar indicando não que a situação descrita pelo verbo ocorreu antes do esperado, mas que o locutor não esperava que a situação em foco ocorresse. Nesse sentido, embora a situação seja possível, embora haja sim uma probabilidade de ocorrência para ela (que era, inclusive, prevista na Constituição do país), o locutor indica, com o uso do advérbio, que não esperaria que de fato ela ocorresse, embora reconheça sua possibilidade. Assim, o advérbio seria indicador não de uma expectativa de ocorrência, mas de um reconhecimento de possibilidade, como destaquei mais acima. Ao indicar não que a situação ocorreu antes do esperado, mas que ela não era de todo esperada, o advérbio continua, no entanto, incidindo sobre a temporalidade do verbo, uma vez que ele permanece indicando que a situação ocorreu antes do momento da enunciação. A questão da temporalidade, embora não seja suspensa, é, contudo, "desfocada", deixa de estar no funcionamento central do advérbio. Nesses casos, o funcionamento do advérbio coloca em cena questões enunciativas, relativas aos sujeitos envolvidos na interação, ao texto em que o enunciado aparece e ao seu contexto de produção. ${ }^{5}$

\footnotetext{
${ }^{4}$ A razão pela qual a criança pode dizer que os pais virão logo abrir a porta é que era possível que eles a abrissem. Se não houvesse essa possibilidade, o enunciado não seria aceitável. Assim, ainda que este não seja o sentido fundamental desse enunciado, seu sentido só se configura em função dessa situação de fundo. 5 A noção de escala argumentativa parece elucidativa desse tipo de ocorrência do advérbio. Essa linha descritiva será explorada em outro momento da pesquisa.
} 


\subsection{A demarcação e a pressuposição}

Como parte do funcionamento desse advérbio, Raposo (2013) destaca ainda a "demarcação" (delimitação, separação) das duas situações relacionadas na frase: aquela descrita pela frase e aquela anterior, quando a situação descrita ainda não tinha ocorrido. A situação anterior é, em geral, apenas sugerida no enunciado, ficando implícita, embora possa eventualmente vir explicitada. De acordo com Raposo (op. cit., p. 1652), "o advérbio incide sobre a parte inicial da nova situação". A demarcação entre as duas situações se relaciona com a expectativa de que a nova situação poderia acontecer, indicando que ela não ocorria antes, mas que passa a acontecer, ou existir, a partir de um certo momento.

A demarcação tem a ver ainda com uma outra característica desse advérbio, a indicação de pressuposição. $O$ advérbio introduz a pressuposição de que a situação descrita pelo verbo não ocorria em um momento anterior (se Pedro já está em casa, é porque em algum momento anterior ele não estava ainda). Assim se dá a demarcação: o advérbio indica que uma situação possível ocorreu ou começou a ocorrer antes do momento da enunciação ou de um momento de referência; além disso, ele indica que a situação não ocorria em um momento anterior e delimita esses dois momentos, um anterior e outro posterior à ocorrência da situação descrita pelo verbo. ${ }^{6}$

\subsection{A estrutura semântica do advérbio já (ou semiótica, em termos benvenistianos)}

Podemos visualizar a estrutura semântica do advérbio já nos quadros abaixo, organizados conforme o tempo e o aspecto do verbo. Os quadros trazem paráfrases para as frases, cujo objetivo é explicitar seus efeitos de sentido relacionando as quatro propriedades identificadas no seu funcionamento. Assim, a expectativa aparece nas paráfrases junto com a localização temporal, na medida em que o advérbio indica que a situação esperada / possível ocorreu em um determinado tempo. ${ }^{7}$ Já a pressuposição e a demarcação aparecem nos enunciados parafrásticos em encadeamentos concessivos, através dos quais pretendi mostrar a relação da localização temporal com a pressuposição, constituindo a demarcação entre as duas situações relacionadas. Os encadeamentos são concessivos, construídos com a conjunção embora, em função do caráter de ressalva da concessão (GUIMARÃES, 2007).

Assim, é possível destacar (marcar), na paráfrase, os efeitos de sentido do advérbio relativos à localização temporal, deixando os efeitos relativos à pressuposição, e à consequente demarcação, como parte dos sentidos implícitos no enunciado. Em outras palavras, o já marca o posto, não o pressuposto; por isso, o pressuposto é introduzido na paráfrase pelo embora e não pelo mas, que marcaria o pressuposto, ao contrário do que faz o advérbio já. Essa opção também possibilita explicar o funcionamento do advérbio

\footnotetext{
${ }^{6}$ Vale lembrar que, se o verbo estiver no futuro, a relação temporal entre a situação descrita pelo verbo e o momento da enunciação (ou o momento de referência) passará a ser uma relação de posterioridade, e não mais de anterioridade, como quando o verbo está em um tempo passado. Em outras palavras, nesse caso, o advérbio indica que uma situação poderá ocorrer depois do momento da enunciação ou de um momento de referência, situação essa que não ocorria em um momento anterior.

${ }^{7}$ Nos quadros a seguir, a expectativa foi incluída, mas apenas para destacá-la; nas paráfrases dos exemplos, a serem apresentadas um pouco adiante no corpo do artigo, ela não será destacada, uma vez que já o foi anteriormente, quando o tema em discussão era especificamente a expectativa.
} 
junto a certos tempos verbais em que o pressuposto parece "sumir de cena", ficar com um conteúdo implícito que não emerge na interpretação da frase.

Quadro 1. Aspecto imperfectivo, tempo presente do indicativo

X já acontece
Era de se esperar que X acontecesse (EXPECTATIVA) e X está acontecendo desde antes do
momento da enunciação (LOCALIZAÇ̃̃̃O TEMPORAL), embora em um momento anterior
ainda nã o acontecesse (PRESSUPOSIÇÃO, DEMARCAÇÃO)

Fonte: Elaboração própria

Quadro 2. Aspecto imperfectivo, tempo pretérito imperfeito

\section{$X$ já acontecia}

Era de se esperar que $\mathrm{X}$ acontecesse (EXPECTATIVA) e X acontecia desde antes de um momento de referência (LOCALIZAÇÃO TEMPORAL), embora em um momento anterior ainda não acontecesse (PRESSUPOSIÇÃO, DEMARCAÇÃO)

Fonte: Elaboração própria

Quadro 3. Aspecto perfectivo, tempo pretérito perfeito

X já aconteceu

Era de se esperar que $\mathrm{X}$ acontecesse (EXPECTATIVA) e $\mathrm{X}$ aconteceu antes do momento da enunciação (LOCALIZAÇÃO TEMPORAL), embora em um momento anterior ainda nãa tivesse acontecido (PRESSUPOSIÇÃO, DEMARCAÇÃO)

Fonte: Elaboração própria

Quadro 4. Aspecto perfectivo, tempo pretérito mais que perfeito

\begin{tabular}{|l|} 
X já tinha acontecido \\
Era de se esperar que X acontecesse (EXPECTATIVA) e X tinha acontecido antes de um \\
momento de referência (LOCALIZAÇ̃̃O TEMPORAL), embora em um momento anterior ainda \\
nã o estivesse (PRESSUPOSIÇÃO, DEMARCAÇÃO)
\end{tabular}

Fonte: Elaboração própria

Quadro 5. Tempo futuro

X já acontecerá

Era de se esperar que X acontecesse (EXPECTATIVA) e X acontecerá depois do momento da enunciação ou de um momento de referência dado no texto ou no contexto (LOCALIZAÇÃO TEMPORAL), embora em um momento anterior ainda nãa tivesse acontecido (PRESSUPOSIÇÃO, DEMARCAÇÃO)

Fonte: Elaboração própria

Retomemos os exemplos 1 a 8, já analisados acima, para observar como funciona a relação entre a localização temporal e a pressuposição, constituindo a demarcação das duas situações relacionadas na frase. Após cada um dos enunciados abaixo, vemos a indicação da sua localização temporal, seguida da pressuposição introduzida pelo já, demarcando as duas situações relacionadas na frase.

(1) Pedro já está em casa.

Pedro está em casa desde antes do momento da enunciação, (embora em um momento anterior ainda não estivesse). 
(2) As possibilidades técnicas para combinar automaticamente as contas de usuários no Facebook e no WhatsApp já existiam em 2014 [quando o acordo de aquisição do WhatsApp pelo Facebook foi analisado pelos órgãos reguladores antitruste da União Europeia].

As possibilidades técnicas existiam desde a análise do acordo de aquisição, (embora em algum momento anterior ainda não existissem).

(3) Pedro já chegou em casa.

Pedro chegou em casa antes do momento da enunciação, (embora em um momento anterior ainda não tivesse chegado).

(4) Pedro já tinha fechado a janela [quando João foi até o quarto verificar se ela estava fechada].

Pedro tinha fechado a janela antes de João verificar se ela estava fechada, (embora em um momento anterior ela ainda não estivesse fechada).

(5) Quando a criança fizer oito anos, já vão ter caído muitos de seus dentes.

Muitos de seus dentes terão caído antes de a criança fazer oito anos, (embora em um momento anterior ainda não tenham caído).

(6) Pedro já vai guardar os brinquedos.

Pedro vai guardar os brinquedos depois do momento da enunciação, (embora em um momento anterior ele ainda ñ̃o os tenha guardado).

(7) Assim que a obra for entregue, um posto da Polícia Militar já irá começar a funcionar para ajudar no policiamento da região do memorial.

O posto da Polícia Militar vai começar a funcionar depois que a obra for entregue, (embora em um momento anterior ele ainda não tenha começado).

(8) Uma parada no ritmo de redução [da taxa Selic] já seria suficiente para colocar um freio no movimento até então tímido de queda dos juros cobrados nos empréstimos bancários.

A parada no ritmo de redução da taxa Selic, se ocorrer, ocorrerá depois do momento da enunciação, (embora em um momento anterior ainda não tenha ocorrido).

Como vemos nos exemplos acima, há uma relação direta entre os advérbios já e ainda, de tal maneira que um corresponde à negação do outro. Esta característica está prevista em Raposo e se mantém para o PB: "A negação lógica de já e ainda corresponde a uma locução em que se usa o outro advérbio deste par em combinação com o operador de negação não; ou seja, a negação de já é ainda não e a negação de ainda é já não". (RAPOSO, 2013, p. 1654).

Assim, o pressuposto das frases em que aparece o advérbio já se faz sempre com a locução ainda não, na medida em que ele corresponde à negação de que a situação descrita pelo verbo ocorresse em um momento anterior. Como veremos mais adiante, o mesmo não vai acontecer com o advérbio ainda, porque, embora ele também seja introdutor de um pressuposto, este não é construído com uma negação.

\section{O advérbio ainda}

Passemos então à descrição e análise das ocorrências do advérbio ainda. Podemos mais uma vez tomar a descrição de Raposo, já que, assim como a do outro advérbio do par, o já, tal descrição parece funcionar também para o PB. Raposo toma o par já e ainda, mas descreve cada um desses operadores de maneira relativamente independente, isto é, destacando eventuais pontos de encontro entre seus funcionamentos, mas não oferecendo descrições paralelas a eles, de maneira a evidenciar suas relações de sentido. Este é, 
contudo, o objetivo deste trabalho, que procura identificar as características desses advérbios que fazem deles um par, e não apenas dois advérbios justapostos.

\subsection{A temporalidade}

Cabe destacar que, embora Raposo não aborde de maneira direta o tema da localização temporal em sua descrição do ainda, ele o faz indiretamente ao dizer que "o advérbio ainda assinala que a situação descrita pela frase subsiste" (RAPOSO, op. cit., p. 1653, grifo meu). Essa parece ser, sem dúvida, uma das características desse advérbio. Os dados analisados permitem afirmar que, assim como para o já, também para o ainda a temporalidade é uma das propriedades do seu funcionamento. Este advérbio indica que a situação descrita pelo verbo ocorre no momento da enunciação ou em um momento de referência dado no tex to ou no contexto e pode permanecer ocorrendo depois dele (ainda que brevemente, por um período bastante curto, imediatamente posterior); isto é, sua temporalidade fala do presente da enunciação (como no exemplo 18 abaixo) ou do momento de referência dado no texto (como no exemplo 20) e pode apontar para o futuro (como se vê nos exemplos 22 e 23), havendo aqui também uma localização temporal, como há para o já.

O advérbio ainda pode também indicar que a situação descrita pelo verbo ocorre até o momento da enunciação (como no exemplo 19) ou até um momento de referência dado no texto ou no contexto (como no exemplo 21$) ;{ }^{8}$ isto é, sua temporalidade pode apontar também um limite ${ }^{9}$ na linha do tempo, colocado seja no presente da enunciação, seja no presente do momento de referência, indicando a localização temporal da situação descrita pelo verbo. Vê-se uma complementariedade com o seu par, já, cuja temporalidade aponta para o passado ou para o futuro. Refiro-me, aqui, obviamente, aos conteúdos postos veiculados por estes advérbios, uma vez que ambos são introdutores de pressuposições que falam do passado, como vimos acima para o já e veremos abaixo para o ainda.

(18) Pedro ainda está em casa. [Aspecto imperfectivo, tempo presente] Pedro está em casa no momento da enunciação e pode permanecer em casa depois disso.

(19) Até agora [o comitê Rio 2016] ainda deve a 8.000 pessoas. [Aspecto imperfectivo, tempo presente]

O comitê Rio 2016 deve a 8.000 pessoas pelo menos até o limite temporal do momento da enunciação e pode continuar devendo depois.

(20) Quando foi forçadamente recrutada pela guerrilha perto de Barrancabermeja [...], [a ex-guerrilheira das Farc, recrutada aos 11 anos,] ainda gostava de brincar de bonecas. [Aspecto imperfectivo, tempo pretérito imperfeito]

A ex-guerrilheira das Farc gostava de brincar de boneca no momento em que foi recrutada pela guerrilha (momento de referência dado no texto) e pode ter permanecido gostando pelo menos no momento imediatamente posterior ao recrutamento.

\footnotetext{
${ }^{8}$ Neves (2000) destaca essa possibilidade de o ainda ser associado não apenas à preposição em, como é o caso do já, mas também à preposição até.

${ }^{9}$ Como os verbos usados nessas construções estão sempre em tempos imperfectivos, a preposição não indica necessariamente que esse limite seja um ponto máximo no tempo além do qual a situação não pode ter continuidade. Pode acontecer de a situação descrita pelo verbo atingir pelo menos esse limite, podendo eventualmente se estender além dele.
} 
(21) Até o mês passado, a ação ainda tramitava na comarca de Flores, cidade vizinha a Serra Talhada. [Aspecto imperfectivo, tempo pretérito imperfeito]

A ação tramitava na comarca de Flores pelo menos até o mês anterior (momento de referência dado no texto), podendo ter continuado tramitando depois.

(22) O que conseguimos provar ainda vai dar muita dor de cabeça para aqueles que fazem do futebol um oficio criminoso. [Tempo futuro do presente]

O que se conseguiu provar vai dar muita dor de cabeça em um momento do futuro não especificado no texto.

(23) Ele [Felipe Melo] ainda precisará cumprir mais uma partida de suspensão contra o BarcelonaEQU, na ida das oitavas de final, no dia 5 de junho. [Tempo futuro do presente]

Felipe Melo precisará cumprir mais uma partida de suspensão em um momento do futuro especificado no texto, a partida das oitavas de final, no dia 5 de junho.

Neves (2000) também destaca essa característica deste par de advérbios. Segundo ela, já e ainda são advérbios de tempo indicadores de "situação relativa". O ainda corresponderia à indicação de um "momento ou período, considerado como subsequente a outro", enquanto o já corresponderia à indicação de um "momento ou período, considerado como precedente de outro".

Ao contrário do já, o advérbio ainda, nos usos em que faz par com o já, ocorre somente com verbos no imperfectivo, uma vez que seus efeitos de sentido implicam a continuidade da situação descrita pelo verbo, o que não seria possível para situações dadas como concluídas, conforme acontece no caso dos verbos no perfectivo. Ele pode ocorrer ainda com tempos futuros, justamente porque traz essa ideia de continuidade. ${ }^{10}$

\subsection{A (contra) expectativa e a pressuposição}

Outra característica do advérbio ainda a se investigar é a indicação de uma expectativa do locutor quanto à situação descrita pelo verbo. Ao que parece, ele indica a expectativa de que essa situação possa se encerrar, deixando de ocorrer, a qualquer momento no futuro; a isso se acrescentaria a expectativa, ainda, de que a situação já tivesse se encerrado, não ocorresse mais no momento da enunciação ou no momento dado como referência. Se assim é, como de fato os dados parecem demonstrar, trata-se de um caso de contra-expectativa, tal como previsto em Raposo e em outros autores. ${ }^{11}$ Junto a essa (contra) expectativa, o advérbio introduz a pressuposição de que a situação já ocorria em um momento anterior. Acrescentando à análise a característica destacada mais acima da temporalidade, temos a seguinte estrutura para este advérbio: embora a situação descrita pelo verbo ocorresse em um momento anterior (pressuposição), era de se esperar que já tivesse deixado de ocorrer (contra-expectativa); porém, ela continua ocorrendo no ou até o momento da enunciação ou o momento de referência (localização temporal).

Não há demarcação, como era o caso com o advérbio já, porque aqui não há duas situações diferentes em momentos distintos, mas uma única situação que se estende por mais de um momento no tempo. Portanto, não há o que demarcar.

\footnotetext{
${ }^{10}$ Há usos deste advérbio, que não serão aqui discutidos (ver p. 1), em que ele aparece tanto com verbos no imperfectivo quanto no perfectivo, assim como conjugado em diversos tempos.

${ }^{11}$ Martelotta (2012), por exemplo, afirma que tanto já quanto ainda são indicadores de contra expectativa.
} 


\subsection{A estrutura semântica do advérbio ainda (ou semiótica, em termos benvenistianos)}

As relações argumentativas internas à paráfrase do ainda são distintas daquelas que encontramos para as paráfrases do advérbio já. A diferença fundamental diz respeito ao fato de que temos, no caso do ainda, uma contra-expectativa, que se liga à pressuposição. $\mathrm{O}$ advérbio introduz a pressuposição de que a situação já ocorria antes, $\mathrm{o}$ que conduz à implicatura de que não deveria mais ocorrer - há uma inversão da orientação argumentativa. O conteúdo posto, todavia, introduz nova inversão da orientação do enunciado, uma vez que sustenta a continuidade da referida situação no momento da enunciação ou de referência - chegamos assim à estrutura embora X ocorresse em $t^{0}$, era de se esperar que já não ocorresse mais $X$ em $t^{l}$; no entanto, X ocorre em $t^{1} .{ }^{12}$ No que diz respeito ao outro advérbio do par, o já, seu aparecimento se funda sobre o conteúdo implícito de que a situação descrita pelo verbo era possível, era de se esperar, para afirmar, como conteúdo posto, que ela de fato ocorre. Não há inversão da orientação argumentativa nesse caso. A inversão se dá uma única vez, na relação do posto com o pressuposto. A estrutura ficaria assim: era possível que $X$ ocorresse em $t^{1} \boldsymbol{e} X$ de fato ocorre em $t^{1}$, embora ainda não ocorresse em $t^{0}$.

Vejamos os quadros relativos ao funcionamento do ainda, bastante semelhantes aos quadros relativos ao funcionamento do já, apresentados mais acima.

\section{Quadro 6. Tempo presente}

$X$ ainda acontece

Embora X acontecesse em um momento anterior (PRESSUPOSIÇÃO), era de se esperar que X já não acontecesse mais (CONTRA-EXPECTATIVA). Porém, X continua acontecendo no ou até o momento da enunciação e pode se estender para além dele (LOCALIZAÇÃO TEMPORAL).

Fonte: Elaboração própria

Quadro 7. Tempo pretérito imperfeito

X ainda acontecia
Embora X acontecesse em um momento anterior (PRESSUPOSIÇÃO), era de se esperar que X já
não acontecesse mais (CONTRA-EXPECTATIVA). Porém, X continua acontecendo no ou até o
momento de referência e pode se estender para além dele (LOCALIZAÇÃO TEMPORAL).

\section{Fonte: Elaboração própria}

Com o verbo em um tempo futuro, vejo duas possibilidades de interpretação, uma delas concernente a contextos em que a situação descrita pelo verbo já ocorre no momento da enunciação e a frase trata da sua continuidade no futuro. Nesse caso, a estrutura seria a seguinte:

\footnotetext{
12 Nesse esquema, " $t$ " " significa o momento da enunciação ou o momento de referência e " $t$ " " significa o momento anterior.
} 


\begin{abstract}
$X$ ainda acontecerá $\rightarrow$
Embora X acontecesse em um momento anterior (PRESSUPOSIÇÃO), era de se esperar que X já não acontecesse mais no futuro (CONTRA-EXPECTATIVA). Porém, X continua acontecendo no ou até o momento de referência dado no texto ou no contexto e pode se estender para além dele (LOCALIZAÇÃO TEMPORAL).
\end{abstract}

Fonte: Elaboração própria

Todavia, há outra possibilidade de funcionamento, concernente a contextos em que a situação descrita pelo verbo não ocorre no/até o momento da enunciação e a frase trata da possibilidade de ela vir a ocorrer no futuro. Nesse caso, não há contra-expectativa, mas sim expectativa de que a situação venha a ocorrer e a posição do locutor fica bastante evidente no enunciado, uma vez que a frase coloca em cena justamente essa expectativa, como uma "previsão" do locutor, afetando inclusive a pressuposição, que é contrária àquela da outra interpretação. Esse funcionamento não será estudado neste trabalho, porque aciona outros conceitos, distintos daqueles mobilizados aqui, tal como a noção de escala argumentativa (DUCROT, 1981). Sua descrição fica adiada para o momento posterior a este artigo. ${ }^{13}$

Retomemos agora os exemplos já analisados em que comparece o advérbio ainda, para verificar como fica sua análise completa. Diferentemente do que fiz para o advérbio já, aqui vou apresentar a análise da (contra) expectativa junto com a análise da pressuposição, porque elas compõem de maneira mais direta os efeitos de sentido promovidos na cadeia por este operador.

(18) Pedro ainda está em casa.

Embora Pedro estivesse em casa antes do momento de enunciação, era de se esperar que ele já não estivesse mais. Contudo, Pedro continua em casa no momento da enunciação e pode permanecer lá depois disso.

(19) Até agora [o comitê Rio 2016] ainda deve a 8.000 pessoas.

Embora o comitê Rio 2016 devesse a 8.000 pessoas, era de se esperar que já não devesse mais. Contudo, o comitê Rio 2016 continua devendo a 8.000 pessoas até o momento da enunciação e pode continuar devendo depois disso.

(20) Quando foi forçadamente recrutada pela guerrilha perto de Barrancabermeja [...], [a exguerrilheira das Farc, recrutada aos 11 anos,] ainda gostava de brincar de bonecas.

Embora a ex-guerrilheira das Farc gostasse de brincar com bonecas antes de ser recrutada pela guerrilha, era de se esperar que já não gostasse mais quando foi recrutada. Contudo, a exguerrilheira das Farc continuava gostando de brincar de bonecas no momento em que foi recrutada e pode ter continuado gostando depois disso.

${ }^{13}$ Sua descrição, de acordo com os critérios utilizados neste momento, poderia ficar assim:

$\mathrm{X}$ ainda acontecerá

Quadro 9. Tempo futuro

Embora X não acontecesse no/até o momento da enunciação (PRESSUPOSIÇÃO), é de se esperar que X venha a acontecer no futuro (EXPECTATIVA). Portanto, o locutor sustenta que X acontecerá no ou até o momento de referência dado no texto ou no contexto e pode se estender para além dele (LOCALIZAÇÃO TEMPORAL).

Fonte: Elaboração própria 
Embora a ação tramitasse na comarca de Flores antes do mês passado, era de se esperar que já ñ̃o tramitasse mais. Contudo, a ação continuava tramitando até o mês passado e pode ter permanecido tramitando depois disso.

O exemplo a seguir traz o verbo no futuro, abrindo para duas interpretações, conforme o contexto. Elas são estruturalmente ambíguas, mas, conforme o enunciado em que as frases apareçam, uma ou outra das interpretações propostas acima, nos quadros 8 e 9 (ver nota 12), poderá ser privilegiada, ou pode acontecer também de o enunciado permanecer ambíguo. No caso de (22), o enunciado não explicita se a situação descrita pelo verbo já aconteceu ou não - embora o contexto privilegie a interpretação de que ainda não aconteceu, de que ainda está por acontecer. Essas duas interpretações ficariam assim:

o que conseguimos provar ainda vai dar muita dor de cabeça para aqueles que fazem do futebol um oficio criminoso.

Interpretação 1

Embora o que se conseguiu provar já tenha dado muita dor de cabeça para aqueles que fazem do futebol um ofício criminoso, era de se esperar que, no futuro, já não desse mais. Porém, o que se conseguiu provar vai continuar dando muita dor de cabeça aos envolvidos no futuro.

Interpretação 2

Embora o que se conseguiu provar não tenha dado dor de cabeça para aqueles que fazem do futebol um ofício criminoso, é de se esperar que, no futuro, venham a dar. Portanto, o locutor sustenta que o que se conseguiu provar vai dar muita dor de cabeça aos envolvidos no futuro.

Convém observar que as relações argumentativas internas às duas interpretações acima são diferentes uma da outra. Enquanto a primeira delas toma como pressuposto que já houve dor de cabeça e marca o contra-argumento de que vai continuar havendo (isto é, faz uma inversão da orientação argumentativa), a segunda interpretação toma como pressuposto que ainda não houve dor de cabeça e marca a conclusão de que haverá (isto é, não inverte a orientação do enunciado).

Antes de concluir, vale destacar que, assim como as paráfrases do já traziam a expressão ainda não, as paráfrases do ainda trazem o já não (embora não o façam no pressuposto, como destaquei acima). Essa característica reforça a hipótese de que temos aqui um par semântico, e não apenas dois advérbios com algumas semelhanças em seus modos de funcionamento. Um outro detalhe importante diz respeito ao fato de que, em ambas essas paráfrases, a negação aparece em conteúdos implícitos no enunciado, seja no pressuposto seja em uma implicatura. Isto é, os sentidos de ambos os advérbios incidem sobre os conteúdos postos nos enunciados em que eles aparecem, mas trazem como conteúdos implícitos a sua negação, sempre constituída com o outro advérbio do par. 


\section{Considerações finais}

As análises acima mostraram haver um certo paralelismo no funcionamento semântico dos advérbios já e ainda, corroborando a hipótese de que se trata de um par semântico, cuja descrição ganha ao considerá-los em conjunto. Como vimos, ambos podem ser descritos a partir dos mesmos conceitos de base - a temporalidade, a expectativa e a pressuposição, sendo a primeira relativa a um conteúdo posto e as duas últimas relativas a conteúdos implícitos. A discussão empreendida neste trabalho levantou, contudo, algumas questões que não puderam ser respondidas no espaço aqui disponível. A primeira delas, mais diretamente ligada à noção de temporalidade, é a questão do aspecto.

Por tradição, esses advérbios vêm sendo descritos e classificados como aspectuais, e este trabalho não destacou essa sua característica, ao contrário, deslocou-a para o tema da temporalidade. É certo, porém, que a diferença de "localização temporal" aqui identificada pode ser eventualmente relida em termos de diferença aspectual, se entendermos que o já não fala do passado, ou do futuro, e o ainda do presente, mas que o já fala do início ou da conclusão de uma situação e o ainda da sua continuidade. Essa linha descritiva, embora não desenvolvida aqui, parece bastante promissora.

Outro aspecto do funcionamento desses advérbios que não foi suficientemente destacado aqui - embora tenha sido mencionado em um ou outro momento e mesmo usado internamente às análises realizadas - diz respeito aos aspectos argumentativos do seu funcionamento. As análises pareceram demonstrar não apenas que as relações argumentativas são fundamentais para a compreensão dos sentidos desses advérbios, mas também que conceitos como o de escalaridade devem ser acionados se se quer obter um quadro mais completo e abrangente do funcionamento semântico e discursivo desse par de advérbios (DUCROT, 1981). Do mesmo modo, os conceitos de pressuposição e subentendido podem ser melhor explorados na descrição, de maneira a elucidar a relação tema-rema promovida nos enunciados em que eles aparecem, assim como o efeito de marcação dos conteúdos postos e não-marcação dos conteúdos pressupostos ou subentendidos (DUCROT, 1987). Esses são temas a desenvolver nesta análise e constituirão os próximos passos da pesquisa.

Nesse sentido, cabe ainda, finalmente, destacar que alguns dos enunciados do corpus da pesquisa não se deixaram descrever a partir dos critérios de análise aqui utilizados. Aparentemente, o uso desses advérbios no discurso, sua colocação em ação por sujeitos de linguagem na "língua-discurso" (como diria Benveniste) coloca em cena outros aspectos do funcionamento da língua e do discurso, que não puderam ser captados na descrição estrutural aqui desenvolvida. Entendo que o conceito de escala argumentativa será de fundamental importância para a compreensão desse funcionamento.

\section{REFERÊNCIAS}

BENVENISTE, E. A forma e o sentido na linguagem. Problemas de linguística geral II. Campinas: Pontes, 1989.

CASTILHO, A. T. Nova gramática do português brasileiro. São Paulo: Contexto, 2010. 
CASTILHO, A. T.; ILARI, R. Advérbios predicadores. In: ILARI, R.; NEVES, M. H. M. (Orgs.). Gramática do português culto falado no Brasil. v 2. Classes de palavras e processos de construção. Campinas: EDUNICAMP, 2008.

DUCROT, O. Princípios de semântica linguística (Dizer e não dizer). São Paulo: Cultrix, 1977 [1972].

. As escalas argumentativas. Provar e dizer: linguagem e lógica. São Paulo: Global, 1981[1973].

. O dizer e o dito. Campinas: Pontes Editores, 1987[1984].

GUIMARÃES, E. Texto e argumentação. 4. ed. Campinas: Pontes, 2007[1987].

LYONS, J. Introdução à linguística teórica. São Paulo: Ed. Nacional, 1979.

MARTELOTTA, M. E. Os circunstanciadores temporais e sua ordenação: uma visão funcional. 1993. 229 f. Tese (Doutorado em Linguística) - Faculdade de Letras, Universidade Federal do Rio de Janeiro, Rio de Janeiro. Disponível em: $<$ http://www.discursoegramatica.letras.ufrj.br/download/tese_doutorado_martelotta.pdf $>$. Acesso em: 30 ago. 2017.

Advérbios - conceito e tendências de ordenação. In: OLIVEIRA, M. R.; CEZARIO, M. M. (Orgs.). Adverbiais: aspectos gramaticais e pressões discursivas. Niterói: EdUFF, 2012.

NEVES, M. H. de M. Gramática de usos do português. São Paulo: UNESP, 2000.

RAPOSO, E. (Org.). Gramática do português. v. II. Coimbra: Fundação Calouste Gulbenkian, 2013.

TRASK, R. L. Dicionário de linguagem e linguística. São Paulo: Contexto, 2004.

ZAMBONI, L. M. S. Análise semântica da palavra ainda. 1978. 97 f. Dissertação (Mestrado em Linguística) - Instituto de Estudos da Linguagem, Universidade Estadual de Campinas, Campinas. Disponível em: $<$ http://www.repositorio.unicamp.br/bitstream/REPOSIP/270469/1/Zamboni_LilianMarci aSimoes_M.pdf>. Acesso em: 30 ago. 2017.

Recebido em: 04/09/2017

Aprovado em: 31/10/2017 